\title{
Attachment-related anxiety is associated with poor genital satisfaction and sexual problems in women
}

\author{
Nikola Komlenac ${ }^{1 *}$ (D) and Margarethe Hochleitner ${ }^{2}$
}

\begin{abstract}
Background: Genital satisfaction has been found to influence women's sexual experience. We tested the Relational Bodily Experiences Theory (RBET) that predicts associations between women's genital satisfaction, attachment models, and sexual desire. We extended the model by additionally considering sexual arousal, orgasmic sensation, or the experience of pain during sexual activity as outcome variables. According to the RBET, women's attachment models are associated with their genital satisfaction and linked to women's sexual experience.
\end{abstract}

Methods: A cross-sectional online questionnaire study was conducted at an Austrian medical university. In total 294 women $\left(M_{\text {age }}=23.7, S D=3.4\right)$ provided full responses. Women were asked about genital satisfaction and experiences of distressing sexual problems. Attachment-related anxiety and avoidance were assessed with the Experiences in Close Relationships-Relationship Structures Questionnaire.

Results: Results partially support the RBET. Attachment-related anxiety was associated with genital satisfaction which, in turn, was linked to experiences of frequent and/or distressing diminished sexual arousal, diminished sexual desire, or pain during sexual activity.

Conclusions: These results suggest that clinicians should assess genital satisfaction when treating female sexual problems. Women with attachment-related anxiety may especially be prone to having poor genital satisfaction and may profit from body image interventions in order to improve their sexual experience.

Keywords: Relational and Bodily Experiences Theory (RBET), Female sexual desire, Attachment, Genital satisfaction, Female sexual problems, Austria

\section{Background}

The Relational Bodily Experiences Theory (RBET) [1] explains the inhibition or heightening of sexual desire in women by using the smallest number of relevant interpersonal and psychological constructs [2]. A previous study [3] showed that in accordance with the RBET, women's attachment models are associated with their sexual body self-representation and sexual body self-representation,

\footnotetext{
*Correspondence: nikola.komlenac@i-med.ac.at

${ }^{1}$ Gender Medicine Unit, Medical University of Innsbruck,

Fritz-Pregl-Strasse 3, 6020 Innsbruck, Austria

Full list of author information is available at the end of the article
}

in turn, is linked to women's sexual desire [1]. However, previous research reports that the two components of the RBET are associated not only with low sexual desire but also with other sexual dysfunctions [4-7]. Sexual dysfunctions in women include distressing experiences of low sexual desire, but also lack of sexual arousal, difficulties in attaining orgasm, and pain during sexual activity $[8,9]$. A recent population-based study in Belgium reports the prevalence of distressing low sexual desire to be $4.9 \%$, of distressing lack of sexual arousal $6.3 \%$, of distressing difficulties in attaining orgasm $4.4 \%$, and of pain during sexual activity $1.5 \%$ [10]. In order to consider all sexual dysfunctions, we tested and extended the RBET by 
including lack of sexual arousal, difficulties in attaining orgasm, and pain during sexual activity in addition to low sexual desire as outcome variables of the model.

Attachment models include peoples' expectations of the availability, responsiveness, approval, or affection of an important (intimate) other person [11, 12]. People who have secure attachment models are confident that the other person is available or responsive and that the important person will always show approval or affection. On the other hand, people who have anxious attachment models are characterized by a lack of such confidence. People with avoidant attachment models have pessimistic views of relationships and avoid intimacy and emotional commitment [11]. Even though first attachment models are formed during infancy based on the availability and responsiveness of an important caretaker [11, 12], those early attachment models do not determine people's attachment models in adulthood [13]. Additionally, by adulthood people often report strongest attachment to partners as compared to friends, siblings or parents [14]. Those attachment models for partners held in adulthood may differ from parent-child attachment models formed during infancy [13, 15-19]. In order to better guide therapy and interventions, Nichols [19] furthermore argued that it would be more informative to focus on current attachment models and their associations with women's sexual functioning than to study parent-child attachment models of adult women. This is why in the current study we focused on attachment models of current or past intimate relationships with potential sexual partners and did not assess attachment models of parent-child relationships, as was done in a previous study [3].

According to the RBET, women's attachment models are associated with their sexual body self-representation [1]. Sexual body self-representation includes the following concepts: sexual subjectivity (i.e. in how far a person regards themselves as a sexual being, and their sense of entitlement to sexual desire and pleasure [20]), self-objectification (i.e. a person's tendency to take an observer's perspective about one's own body and judge oneself on the basis of whether the body fulfills social (heteronormative) expectations [21]), and genital self-image. Genital self-image refers to a person's perceptions, thoughts and feelings about their genitalia. Positive evaluations of one's genitalia result in genital satisfaction [22]. The Object of Desire Self-Consciousness Theory [23] gives a rationale for the relationship between attachment models and women's genital satisfaction. According to the Object of Desire Self-Consciousness Theory [23], the assumption of not being romantically and sexually desirable to potential sexual partners is associated with poor body image. This is why especially women with attachment-related anxiety, who are often characterized as being fearful, feeling insecure about being a desirable partner or having negative self-appraisals or having low self-esteem [11, 24], may develop poor body image, including poor genital self-image. It was found that poor genital self-image is positively associated with low sexual desire, lack of sexual arousal, difficulties in attaining orgasm, and pain during sexual activity $[4,5,25,26]$. In the current study, genital satisfaction was considered, because of the salience of genital satisfaction with regard to women's sexual activity and female sexual pleasure [27].

In summary, the RBET has been supported by past research [3] and highlights the importance of attachment models and women's sexual body self-representation in understanding women's problems with sexual desire [1]. Therefore, attachment-based interventions and body image interventions [28] may be considered when treating low sexual desire in women. However, components of the RBET are associated not only with low sexual desire but also with other sexual dysfunctions [4-7], and clinicians may need to consider women's attachment models and their sexual body self-representation not only when treating women with low sexual desire, but also with other sexual dysfunctions. The current study is one of the rare studies to analyze the associations between female attachment models, genital satisfaction and sexual dysfunctions [29]. The aim of the study was to empirically test and extend the RBET by considering all sexual dysfunctions $[8,9]$, including low sexual desire, lack of sexual arousal, difficulties in attaining orgasm, and pain during sexual activity as outcome variables.

\section{Methods}

\section{Procedure and measures}

The current study was part of a larger study regarding young adult pornography consumption and sexual health. This online questionnaire study was conducted at an Austrian medical university. All medical students at this medical university were contacted by e-mail and invited to participate in the study that was hosted on SoSci: der onlineFragebogen (https://soscisurvey.de/). Participants provided informed consent before accessing the questionnaire. Participation was voluntary, anonymous and all participants were able to withdraw from participation at any time. Authors' contact information was provided on every page of the online questionnaire and participants were able to contact the authors for any questions concerning the study. The medical university's Ethics Committee exempted the current study from full ethics review.

The first part of the questionnaire contained questions about sociodemographic variables. Participants were asked to self-report their gender ("woman", "man", "other"), their age, their sexual orientation 
("heterosexual", "gay-identified/lesbian-identified", "bisexual", "asexual", "other"), their nationality ("Austrian" vs. "German" vs. "Turkish" vs. "Italian" vs. "other") and their relationship status ("single" vs. "in relationship"). For any participant who chose "other" as a response an additional open text field allowed the response to be specified. The current analysis included only female participants. Because only a small percentage $(2.0 \%)$ identified as lesbian, a dichotomous variable was formed for sexual orientation. Lesbianidentified and bisexual women (12.9\%) were grouped in one category of the newly formed dummy variable for sexual orientation (non-heterosexual identified). Heterosexual-identified women $(85.0 \%)$ were grouped in the other category.

Distressing sexual problems were assessed with two questions [30]. First, participants were asked how often (1=never, 2 =sometimes, $3=$ often, $4=$ always $)$ they had experienced each of the following sexual problems in the previous 6 months: pain during sexual activity, diminished sexual desire, diminished sexual arousal, or diminished intensity of orgasmic sensations. If prevalent, participants were asked how much distress $(1=$ no distress, $2=$ a little, $3=$ considerable, $4=$ much distress) they felt in connection with each sexual problem. Responses to these two questions were multiplied to form one (continuous) variable for each distressing sexual problem, so that the variable contains information about the frequency of a sexual problem and the distress caused by such a problem $[8,10,31,32]$.

To assess women's satisfaction with their genitalia an item based on The Body Parts Satisfaction ScaleRevised [33] or The Female Genital Self-Image Scale [5] was formulated. Women were asked, "How satisfied are you with the appearance of your genitalia?" Participants indicated their satisfaction with this body part on a sixpoint Likert scale ( $1=$ not at all, $6=$ totally satisfied $)$.

The Experiences in Close Relationships-Relationship Structures Questionnaire (ECR-RS) assesses attachment-related anxiety (Cronbach's $\alpha=0.83-0.91$; three items) and attachment-related avoidance (Cronbach's $\alpha=0.81-0.87$; six items) [34]. Responses were given on a 7-point Likert scale $(1=$ low attachment-related anxiety or avoidance; $7=$ high attachment-related anxiety or avoidance). Only participants who responded to this part of the questionnaire with regard to their current or past partners were considered in the current study. In the current study the attachment-related anxiety scale achieved a reliability of Cronbach's $\alpha=0.85$ (three items). Two items (Item 5 and Item 6) from the attachment-related avoidance scale were removed because of low loadings $(\lambda<0.5)$ on the factor for attachment-related avoidance in the structural equation model. The reliability of the shortened attachment-related avoidance scale was Cronbach's $\alpha=0.87$ (four items).

\section{Statistical analysis}

Descriptive statistics concerning participants' responses included the percentages and means (standard deviations) of given responses. Spearman correlations between the variables that were included in the subsequent structural equation model (SEM) were calculated. For those analyses the Statistical Package for the Social Sciences (SPSS) for Windows, version 25.0 (IBM Corp., Armonk, NY, USA) was used.

The SEM tested the relationships between attachmentrelated anxiety or avoidance, genital satisfaction and distressing sexual problems (Fig. 1). In the model each distressing sexual problem was predicted by genital satisfaction and attachment-related anxiety or avoidance. Furthermore, paths were calculated between attachmentrelated anxiety or avoidance and genital satisfaction. Indirect effects of attachment-related anxiety or avoidance on distressing sexual problems through genital satisfaction were estimated. Confidence intervals for the indirect model parameters were estimated with the Bollen-Stine bootstrap method using 500 bootstrap samples [35, 36]. The model was controlled for the sociodemographic variables age, sexual orientation and relationship status. The SEM was calculated using MPlus, Version 8 [36] (Muthén \& Muthén, Los Angeles, CA, USA).

The mean-adjusted chi-square test statistic was used to determine model fit $[36,37]$, because variables violated the assumption of normal distribution (values of skew ranged from - 1.02 to 2.59 and values of kurtosis ranged from 0.38 to 9.16 ) [38]. A good model fit with the data was assumed when the following conditions were met: $p$ values $\leq 0.05$, ratio between chi-square statistics and respective degrees of freedom $\left(x^{2} / d f\right) \leq 3.0$ [39], root mean square error of approximation (RMSEA) $\leq 0.08$ [40], standardized root mean square residual $(\mathrm{SRMR}) \leq 0.10$, comparative fit index $(\mathrm{CFI}) \geq 0.90$ [39] The level of significance for all analyses was $\alpha=0.05$.

\section{Results \\ Participants}

In total 419 female participants took part in the online questionnaire study. Of the respondents, 115 were excluded because they reported their attachment with regard to friends or parental figures. Additional ten respondents were excluded from the analysis because they did not provide full responses to all questions relevant to the study. Finally, responses from 294 women $\left(M_{\text {age }}=23.7, \quad S D=3.4 ; \quad\right.$ range $=18-46$ years $)$ were included in the analysis. Most women (59.2\%) indicated having Austrian nationality. Additional nationalities 


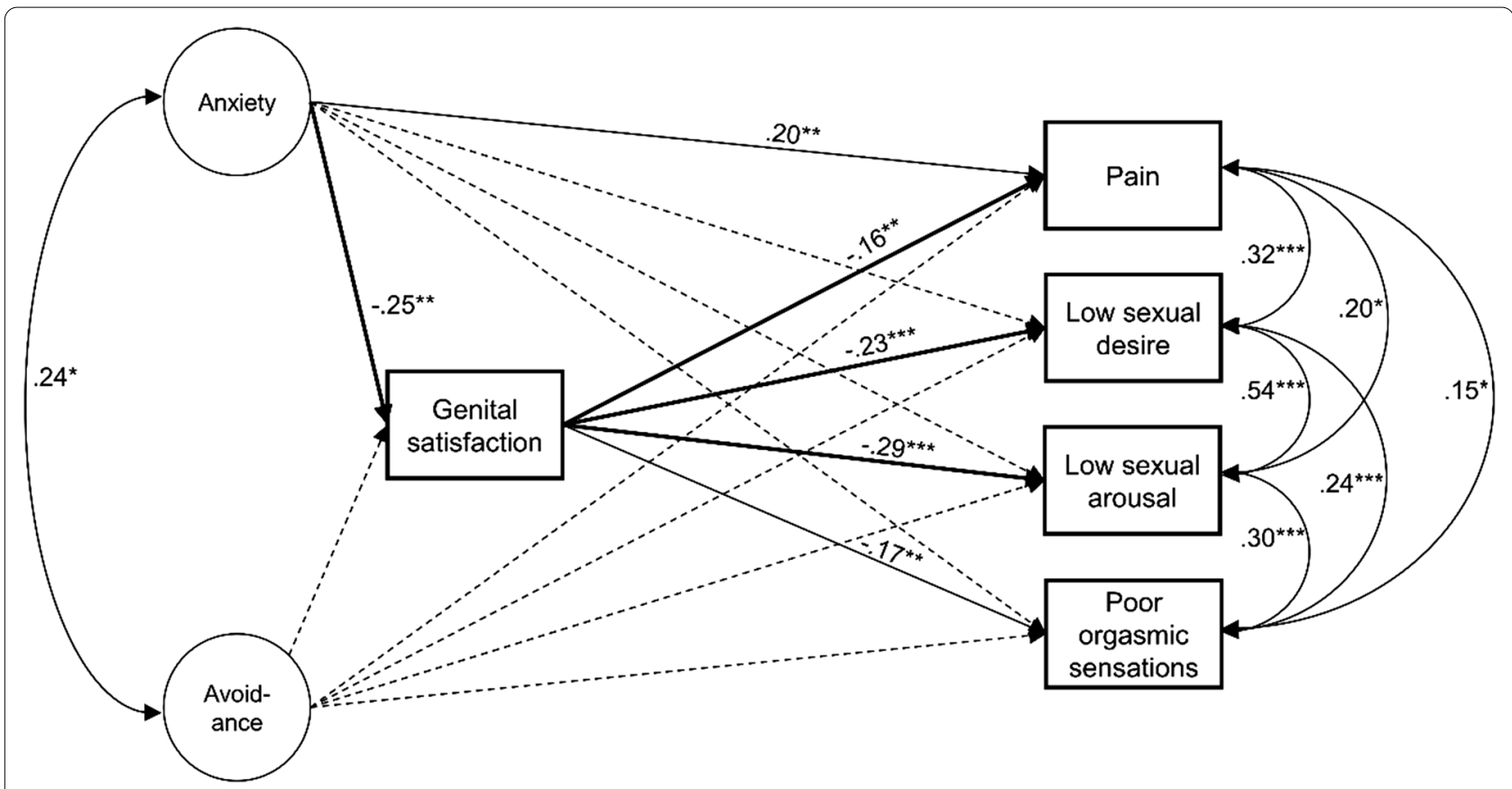

Fig. 1 Structural equation model testing the Relational and Bodily Experience Theory. Note The structural equation model tested the Relational and Bodily Experience Theory. In the model the association between attachment-related anxiety or avoidance and sexual problems is estimated with mediating effects of genital satisfaction. The model was controlled for the sociodemographic variables age, sexual orientation and relationship status. Dotted lines represent non-significant relations; bold lines represent significant indirect paths. ${ }^{*} p \leq 0.05,{ }^{* *} p \leq 0.01,{ }^{* * *} p \leq 0.001$

reported were: German (21.1\%), Italian (16.3\%), or other (3.4\%). Most women (85.0\%) self-reported having a heterosexual sexual orientation. The majority (77.2\%) of the participants were in a relationship at the time of the study.

\section{Descriptive statistics}

Most women reported little attachment-related anxiety or avoidance. The majority of women reported being satisfied with their genitalia (Table 1). With regard to diminished sexual desire, $44.9 \%$ of the participants had never experienced such difficulties.

Table 1 Means and Spearman correlations $(n=294)$

\begin{tabular}{|c|c|c|c|c|c|c|c|c|c|c|c|}
\hline & $M(S D) ;$ range & 2 & 3 & 4 & 5 & 6 & 7 & 8 & 9 & 10 & 11 \\
\hline 1. Age & $23.7(3.4) ; 18-46$ & $0.12^{*}$ & 0.08 & 0.02 & -0.03 & 0.08 & $0.13^{*}$ & $-0.13^{*}$ & -0.08 & -0.07 & -0.04 \\
\hline 2. Nationality ${ }^{\mathrm{a}}$ & & & $-0.13^{*}$ & -0.01 & 0.02 & 0.07 & 0.00 & -0.08 & -0.04 & -0.02 & 0.05 \\
\hline 3. Relationship status ${ }^{b}$ & & & & 0.02 & $-0.33^{* *}$ & $-0.33^{* *}$ & 0.01 & 0.02 & $0.16^{* *}$ & $0.14^{*}$ & -0.03 \\
\hline 4. Sexual orientationc & & & & & -0.07 & -0.03 & 0.01 & 0.01 & 0.07 & $0.15^{* *}$ & -0.03 \\
\hline 5. Anxiety & $2.5(1.5) ; 1-7$ & & & & & $0.45^{* *}$ & $-0.19^{* *}$ & 0.11 & -0.01 & 0.02 & $0.16^{* *}$ \\
\hline 6. Avoidance & $1.6(0.9) ; 1-7$ & & & & & & $-0.17^{* *}$ & 0.06 & 0.06 & 0.07 & $0.22^{* *}$ \\
\hline 7. Genital satisfaction & $4.7(1.2) ; 1-6$ & & & & & & & $-0.19^{* *}$ & $-0.25^{* *}$ & $-0.22^{* *}$ & $-0.22^{* *}$ \\
\hline 8. Pain & $2.5(2.4) ; 1-16$ & & & & & & & & $0.33^{* *}$ & $0.26^{* *}$ & $0.12^{*}$ \\
\hline 9. Low sexual desire & $3.2(2.8) ; 1-16$ & & & & & & & & & $0.44^{* *}$ & $0.31^{* *}$ \\
\hline 10. Low sexual arousal & $2.1(2.0) ; 1-12$ & & & & & & & & & & $0.30^{* *}$ \\
\hline 11. Poor orgasmic sensations & $2.8(2.7) ; 1-16$ & & & & & & & & & & \\
\hline
\end{tabular}

\footnotetext{
a The baseline was Austrian $=1($ German $=2$, Italian =3, other $=4)$

b The baseline was single $=1$ (in relationship $=2$ )

c The baseline was heterosexual-identified $=1$ (non-heterosexual-identified $=2)$

${ }^{*} p \leq 0.05,{ }^{* *} p \leq 0.01$
} 
Of the participants $56.1 \%$ reported that they had not experienced pain during sexual activity in the previous 6 months. In the previous 6 months $66.7 \%$ of the participants had not experienced diminished sexual arousal, whereas $48.6 \%$ had not experienced diminished intensity of orgasmic sensations. The means of the composite variables of the distressing sexual problems (Table 1) indicate that $4.8 \%$ of the women experienced frequent and/or distressing pain during sexual activity (composite value $\geq 8$ ). With regard to diminished sexual desire, $7.8 \%$ of women experienced such a difficulty frequently and/or were considerably distressed by it. In the previous 6 months $3.8 \%$ of the participants had frequent and/or distressing experiences of diminished sexual arousal, whereas $8.6 \%$ had frequent and/or distressing experiences of diminished intensity of orgasmic sensations.

Bivariate correlations between variables are reported in Table 1. Attachment-related anxiety and avoidance were negatively correlated with genital satisfaction. Women who reported poor genital satisfaction were more likely to report frequent and/or distressing experiences of each sexual problem studied. There was a positive association between attachment-related anxiety or avoidance and the experienced diminished intensity of orgasmic sensations.

\section{Testing the Relational and Bodily Experiences Theory}

The structural equation model proved to have a good fit with the data, $\mathrm{X}^{2}(53)=149.6, p<0.001 ; \mathrm{X}^{2} / d f=2.8$; RMSEA $=0.079, \quad 90 \%$ CI $\quad[0.064-0.094] ; \quad C F I=0.937$; $\mathrm{SRMR}=0.051$. All path coefficients of direct effects are reported in Table 2. While controlling for age, sexual orientation and relationship status the negative association between attachment-related anxiety and genital satisfaction remained significant (Fig. 1). On the other hand, attachment-related avoidance was not associated with genital satisfaction or with any sexual problem when controlling for age, sexual orientation and relationship status. Genital satisfaction was linked to women's experiences of sexual problems. Women with poor genital satisfaction were more likely to experience frequent and/or distressing experiences of diminished sexual desire, diminished sexual arousal, diminished intensity of orgasmic sensations, or pain during sexual activity (Fig. 1). In addition, attachment-related anxiety was positively associated with the experience of frequent and/or distressing experiences of pain during sexual activity (Fig. 1). In total, the model explained $11 \%$ of variance of the experiences of diminished sexual desire, $19 \%$ of variance of diminished sexual arousal, $6 \%$ of variance of diminished intensity of orgasmic sensations, and $9 \%$ of variance of pain during sexual activity. The analyses of indirect effects were performed only to analyze the indirect effect of attachment-related

Table 2 Path coefficients of direct effects in the structural equation model testing the Relational and Bodily Experience Theory

\begin{tabular}{|c|c|c|c|c|c|c|}
\hline \multirow[t]{2}{*}{ Predictor variable } & \multirow[t]{2}{*}{ Outcome variable } & \multirow[t]{2}{*}{$B$} & \multirow[t]{2}{*}{$S E B$} & \multirow[t]{2}{*}{$\beta$} & \multicolumn{2}{|c|}{$95 \% \mathrm{Cl}$ for $\beta$} \\
\hline & & & & & $L L$ & $U L$ \\
\hline \multirow[t]{6}{*}{ Attachment-related anxiety } & & & & & & -0.11 \\
\hline & Gential satisfaction & $-0.22^{* *}$ & 0.07 & $-0.25^{* *}$ & -0.38 & \\
\hline & Pain & $0.36^{*}$ & 0.15 & $0.20^{* *}$ & 0.08 & 0.32 \\
\hline & Low sexual desire & 0.02 & 0.19 & 0.01 & -0.12 & 0.15 \\
\hline & Low sexual arousal & 0.15 & 0.13 & 0.10 & -0.03 & 0.24 \\
\hline & Poor orgasmic sensations & 0.20 & 0.15 & 0.10 & -0.02 & 0.22 \\
\hline \multirow[t]{6}{*}{ Attachment-related avoidance } & & & & & & 0.05 \\
\hline & Gential satisfaction & 0.08 & 0.10 & 0.06 & -0.18 & \\
\hline & Pain & 0.05 & 0.18 & 0.02 & -0.07 & 0.12 \\
\hline & Low sexual desire & 0.16 & 0.22 & 0.05 & -0.04 & 0.16 \\
\hline & Low sexual arousal & 0.19 & 0.15 & 0.08 & -0.01 & 0.19 \\
\hline & Poor orgasmic sensations & 0.23 & 0.34 & 0.07 & -0.08 & 0.28 \\
\hline \multirow[t]{5}{*}{ Gential satisfaction } & & & & & & -0.06 \\
\hline & Pain & $-0.32^{*}$ & 0.13 & $-0.16^{* *}$ & -0.26 & \\
\hline & Low sexual desire & $-0.54^{* * *}$ & 0.15 & $-0.23^{* * *}$ & -0.33 & -0.13 \\
\hline & Low sexual arousal & $-0.51^{* * *}$ & 0.13 & $-0.29^{* * *}$ & -0.41 & -0.18 \\
\hline & Poor orgasmic sensations & $-0.40^{* *}$ & 0.14 & $-0.17^{* *}$ & -0.28 & -0.07 \\
\hline
\end{tabular}

$\mathrm{X}^{2}(53)=149.6, p<0.001 ; \mathrm{X}^{2} / d f=2.8 ; \mathrm{RMSEA}=0.079,90 \% \mathrm{Cl}[.064-.094] ; \mathrm{CFI}=0.937 ; \mathrm{SRMR}=0.051 ; \mathrm{Cl}=$ confidence interval ${ }^{*} p \leq 0.05 ;{ }^{* *} p \leq 0.01 ;{ }^{* * *} p \leq 0.001$ 
anxiety on the sexual problems through genital satisfaction, because of the non-significant associations between attachment-related avoidance and the other variables (Fig. 1). The analysis of indirect effects revealed that attachment-related anxiety had an indirect effect on diminished sexual desire, diminished sexual arousal, and pain during sexual activity through genital satisfaction (Table 3).

\section{Discussion}

The current study adds partial support for the Relational Bodily Experience Theory (RBET) [1]. According to the RBET, women's attachment models are associated with their sexual body self-representation. Sexual body selfrepresentation, in turn is linked to women's sexual desire [1]. The current study's findings reveal that attachmentrelated anxiety is associated with genital satisfaction and is consequently linked to experiences of frequent and/or distressing diminished sexual desire. Our study extends previous findings [3] by extending the model. Our study adds the finding that women's attachment models and genital satisfaction are not only related to sexual desire, but are also associated with the experience of sexual arousal or the experience of pain during sexual activity.

Our study's results are in line with studies that found that attachment-related anxiety, in particular, is a strong predictor for body dissatisfaction [41], body surveillance, or body shame [42]. Women with attachment-related anxiety, who are afraid they would not receive approval or affection from an important intimate person [11], may also doubt that they are romantically and sexually desirable in another's eyes. The Object of Desire SelfConsciousness Theory [23] explains that people who doubt that they are romantically and sexually desirable in another's eyes may also develop poor body image. Poor body image, including poor genital satisfaction may lead to distracting thoughts about one's genitalia during sexual activity. Such cognitive distraction often negatively impacts sexual activity $[6,43,44]$. In accordance, in the

Table 3 Indirect effects of attachment-related anxiety on sexual problems through genital satisfaction

\begin{tabular}{lllllll}
\hline Sexual problem & $B$ & SE $B$ & $\beta$ & \multicolumn{2}{c}{$\mathbf{9 5 \%}$ Cl for $\boldsymbol{\beta}$} \\
\cline { 5 - 7 } & & & & $\boldsymbol{L L}$ & $\boldsymbol{U L}$ \\
\hline Pain & 0.07 & 0.04 & $0.04^{*}$ & 0.01 & 0.08 \\
Low sexual desire & $0.12^{*}$ & 0.05 & $0.06^{*}$ & 0.03 & 0.11 \\
Low sexual arousal & $0.11^{*}$ & 0.05 & $0.07^{*}$ & 0.03 & 0.13 \\
Poor orgasmic sensations & 0.09 & 0.05 & 0.04 & 0.01 & 0.09
\end{tabular}

$\mathrm{X}^{2}(53)=149.6, p<0.001 ; \mathrm{X}^{2} / d f=2.8 ; \mathrm{RMSEA}=0.079,90 \% \mathrm{Cl}[.064-.094] ;$ $\mathrm{CFI}=0.937 ; \mathrm{SRMR}=0.051 ; \mathrm{Cl}=$ confidence interval

* $p \leq 0.05$ current study, poor genital satisfaction was associated with sexual problems, such as low sexual desire, experience of sexual arousal problems, experience of poor orgasmic sensation, or the experience of pain during sexual activity.

By extending the RBET the current study shows that attachment models and sexual body self-representation may not only be relevant when treating women with low sexual desire [1], but also with other sexual dysfunctions $[8,9]$, such as lack of sexual arousal, difficulties in attaining orgasm, and pain during sexual activity. Clinicians who treat women with sexual problems should address their clients' or patients' body satisfaction including genital satisfaction. Body image interventions [28] and especially those that help clients or patients prioritize body functionality over body aesthetics [45-47] may help women develop a positive body image and this may consequently improve their sexual experience. The RBET highlights that such body image interventions should also consider women's attachment models because attachment models are associated with body dissatisfaction [41]. Emotionally focused therapies that emphasize attachment-related needs may be considered for women with attachment-related anxiety [48] because of the close association between attachment-related anxiety, genital satisfaction and sexual activity [49].

In our study, however, attachment-related anxiety and genital satisfaction could explain only small to medium proportions of variance for the experiences of frequent and/or distressing sexual problems, including sexual desire [50]. Even though the authors of the RBET tried to explain sexual desire in women by using the smallest number of relevant interpersonal and psychological constructs [2], many other interpersonal and psychological factors not included in the RBET have been found to be associated with distressing sexual problems [51, 52] or genital satisfaction [53]. Future studies should explore whether the model can be extended by factors such as internalization of gender role norms, exposure to peer influence, exposure to media, or depression or anxiety, all of which have been associated with distressing sexual problems or genital satisfaction [25, 51-53].

The current study tested only specific aspects of the RBET and did not include all concepts integrated in the model. For instance, we used only one aspect of the proposed concept for sexual body self-representation, namely genital satisfaction. We tested only genital satisfaction, because of the salience of genital satisfaction with regard to women's sexual activity and female sexual pleasure [27]. Additionally, in a previous study that tested the RBET [3], not all of the hypnotized components of sexual body self-representation (i.e. sexual subjectivity, self-objectification, and genital satisfaction) had strong 
loadings on this one factor. Therefore, analyzing those components separately may be more informative and conclusive in future.

\section{Limitations}

This study has its limitations. First, the current study cannot make any predictions or conclusions about the directionality or causality of found associations, because the results are based on a cross-sectional study. Future longitudinal studies or experimental studies could shed light into the directionality of found associations. Furthermore, the study was conducted in a convenience sample of medical students and results should therefore be interpreted with caution and not be overgeneralized. Second, we used only one self-constructed item for the assessment of genital satisfaction instead of a validated scale [5] in order to keep the questionnaire short and not risk discontinuation by participants before reaching the end of the questionnaire. However, the used item is similar to questions used in validated questionnaires $[5,33]$ and results should therefore be comparable. Nevertheless, future studies should refrain from using self-constructed items that were not subject to psychometric analysis. Last, as is the case with many questionnaire studies, the current study is based on self-reports and may have been biased by participants' inaccurate responses. Some participants may have given inaccurate responses because of social desirability, they may have felt some questions to be intrusive, or they may have had problems understanding some questions on the questionnaire [54].

\section{Conclusions}

In spite of the study's limitations, this is one of the rare studies to test the association between female attachment models, genital satisfaction and sexual desire [29]. The associations that were theoretically predicted by the Relational Bodily Experience Theory (RBET) are partially supported by the current study's results. Attachmentrelated anxiety, but not attachment-related avoidance, was associated with genital satisfaction. Genital satisfaction, in turn, was linked to experiences of frequent and/ or distressing diminished sexual desire. The current study also shows that the factors that predicted sexual desire in the RBET may also influence other components of sexual activity, such as sexual arousal, the experience of orgasmic sensation or the experience of potential pain during sexual activity. It can be recommended that clinicians who treat women with sexual problems also assess their clients' or patients' body satisfaction including genital satisfaction. Body image interventions may be considered an important treatment option for female sexual problems, especially when treating women with attachmentrelated anxiety.

\section{Abbreviations}

RBET: The Relational Bodily Experience Theory; ECR-RS: The Experiences in Close Relationships-Relationship Structures Questionnaire; SEM: Structural equation model; RMSEA: Root mean square error of approximation; SRMR: Standardized root mean square residual; CFI: Comparative fit index.

\section{Acknowledgements}

Not applicable.

\section{Authors' contributions}

$\mathrm{NK}$ and $\mathrm{MH}$ designed the research. NK collected the data. NK analyzed and interpreted the data. NK wrote the manuscript. Both authors read and approved the final manuscript.

\section{Funding}

No funding to declare.

\section{Availability of data and materials}

The datasets used and/or analyzed during the current study are available from the corresponding author on reasonable request.

\section{Ethics approval and consent to participate}

The medical university's Ethics Committee exempted the current study from full ethics review. The study was in accordance with the Declaration of Helsinki [55] and the American Psychological Association standards [56]. All participants gave written informed consent.

\section{Consent for publication}

Not applicable.

\section{Competing interests}

No competing interests to declare.

\section{Author details}

${ }^{1}$ Gender Medicine Unit, Medical University of Innsbruck, Fritz-Pregl-Strasse 3, 6020 Innsbruck, Austria. ${ }^{2}$ Gender Medicine Unit, Medical University of Innsbruck, Innrain 66, 6020 Innsbruck, Austria.

Received: 9 March 2020 Accepted: 26 October 2020

Published online: 30 November 2020

\section{References}

1. Cherkasskaya E, Rosario M. The Relational and Bodily Experiences Theory of sexual desire in women. Arch Sex Behav. 2019a;45:1659-81.

2. Cherkasskaya E, Rosario M. Relational and Bodily Experiences Theory: attachment and sociocultural influences in a parsimonious model of sexual desire in women. Arch Sex Behav. 2019b;48:1719-22.

3. Cherkasskaya E, Rosario M. A model of female sexual desire: internalized working models of parent-child relationships and sexual body selfrepresentations. Arch Sex Behav. 2017;46:2429-44.

4. Komarnicky T, Skakoon-Sparling S, Milhausen RR, Breuer R. Genital self-image: associations with other domains of body image and sexual response. J Sex Marital Ther. 2019;45:524-37.

5. Herbenick D, Schick V, Reece M, Sanders S, Dodge B, Fortenberry JD. The Female Genital Self-Image Scale (FGSIS): results from a nationally representative probability sample of women in the United States. J Sex Med. 2011:8:158-66.

6. Barlow DH. Causes of sexual dysfunction: the role of anxiety and cognitive interference. J Consult Clin Psychol. 1986;54:140-8.

7. Silva E, Pascoal PM, Nobre P. Beliefs about appearance, cognitive distraction and sexual functioning in men and women: a mediation model based on cognitive theory. J Sex Med. 2016;13:1387-94.

8. American Psychiatric Association. Diagnostic and statistical manual of mental disorders (DSM-5). London: American Psychiatric Publishing; 2013. 
9. WHO. Internationale Klassifikation psychischer Störungen: ICD-10 Kapitel $\checkmark$ (F) Klinisch-diagnostische Leitlinien. Dilling H, Mombour W, Schmidt MH, editors. Bern: Verlag Hans Huber, Hogrefe; 2008.

10. Hendrickx L, Gijs L, Enzlin P. Sexual difficulties and associated sexual distress in Flanders (Belgium): a representative population-based survey study. J Sex Med. 2016;13:650-68.

11. Hazan C, Shaver PR. Attachment as an organizational framework for research on close relationships. Psychol Inq. 1994;5:1-22.

12. Bowlby J. Attachment and loss: volume II: separation, anxiety and anger. New York: Basic Books; 1973. p. 1-429.

13. Fraley RC, Roisman Gl. The development of adult attachment styles: four lessons. Curr Opin Psychol. 2019;25:26-30.

14. Doherty NA, Feeney JA. The composition of attachment networks throughout the adult years. Pers Relatsh. 2004;11:469-88.

15. Pinquart M, Feußner C, Ahnert L. Meta-analytic evidence for stability in attachments from infancy to early adulthood. Attach Hum Dev. 2013;15:189-218.

16. Fraley RC. Attachment in adulthood: recent developments, emerging debates, and future directions. Annu Rev Psychol. 2019;70:401-22.

17. Klohnen EC, Weller JA, Luo S, Choe M. Organization and predictive power of general and relationship-specific attachment models: one for all, and all for one? Pers Soc Psychol Bull. 2005;31:1665-82.

18. McConnell M, Moss E. Attachment across the life span: factors that contribute to stability and change. Austr J Educ Dev Psychol. 2011;11:60-77.

19. Nichols M. Expanding our understanding of women's sexual desire. Arch Sex Behav. 2019:48:1699-701.

20. Zimmer-Gembeck MJ, French J. Associations of sexual subjectivity with global and sexual well-being: a new measure for young males and comparison to females. Arch Sex Behav. 2016:45:315-27.

21. Fredrickson BL, Roberts T-A. Objectification theory: toward understanding women's lived experiences and mental health risks. Psychol Women Q. 1997;21:173-206

22. Grogan S. Body image: understanding body dissatisfaction in men, women and children. New York: Routledge; 2016.

23. Bogaert AF, Brotto LA. Object of Desire self-consciousness theory. J Sex Marital Ther. 2014;40:323-38.

24. Mikulincer M, Shaver PR. The attachment behavioral system in adulthood: activation, psychodynamics, and interpersonal processes. Adv Exp Soc Psychol. 2003;35:56-152.

25. Berman LA, Berman J, Miles M, Pollets DAN, Powell JA. Genital self-image as a component of sexual health: relationship between genital selfimage, female sexual function, and quality of life measures. I Sex Marital Ther. 2003;29:11-21.

26. Berman L, Windecker MA. The relationship between women's genital selfimage and female sexual function: a national survey. Curr Sex Health Rep. 2008;5:199-207.

27. Braun V. In search of (better) sexual pleasure: female genital 'cosmetic' surgery. Sexualities. 2005;8:407-24.

28. Alleva JM, Sheeran P, Webb TL, Martijn C, Miles E. A meta-analytic review of stand-alone interventions to improve body image. PLOS ONE. 2015;10:e0139177.

29. Velotta N, Schwartz P. Developing an integrative approach to female sexual desire: the advances and drawbacks of Relational and Bodily Experiences Theory. Arch Sex Behav. 2019;48:1715-8.

30. Komlenac N, Siller H, Bliem HR, Hochleitner M. Associations between gender role conflict, sexual dysfunctions, and male patients' wish for physician-patient conversations about sexual health. Psychol Men Masc. 2019;20:337-46.

31. Mitchell KR, Jones KG, Wellings K, Johnson AM, Graham CA, Datta J, et al. Estimating the prevalence of sexual function problems: the impact of morbidity criteria. J Sex Res. 2016;52:955-67.

32. Hendrickx L, Gijs L, Enzlin P. Age-related prevalence rates of sexual difficulties, sexual dysfunctions and sexual distress in heterosexual men: results from an online survey in Flanders. Sex Relatsh Ther. 2019;34:440-61.

33. Petrie TA, Tripp MM, Harvey P. Factorial and construct validity of the Body Parts Satisfaction Scale-Revised: an examination of minority and nonminority women. Psychol Women Q. 2002;26:213-21.

34. Fraley RC, Heffernan ME, Vicary AM, Brumbaugh CC. The experiences in close relationships—Relationship Structures Questionnaire: a method for assessing attachment orientations across relationships. Psychol Assess. 2011;23:615-25.

35. Bollen KA, Stine R. Direct and indirect effects: classical and bootstrap estimates of variability. Sociol Methodol. 1990;20:115-40.

36. Muthén LK, Muthén BO. Mplus user's guide. Los Angeles: Muthén \& Muthén; 1998-2017.

37. Satorra A, Bentler PM. A scaled difference chi-square test statistic for moment structure analysis. Psychometrika. 2001;66:507-14.

38. Weston R, Gore PA. A brief guide to structural equation modeling. Couns Psychol. 2006;34:719-51.

39. Weiber R, Mühlhaus D. Strukturgleichungsmodellierung: Eine anwendungsorientierte Einführung in die Kausalanalyse mit Hilfe von AMOS, SmartPLS und SPSS. 2nd, extended and corrected ed. Berlin: Springer; 2014.

40. Browne MW, Cudeck R. Alternative ways of assessing model fit. In: Bollen KA, Long JS, editors. Testing structural equation models, vol. 154. London: Sage Publications; 1993. p. 136-62.

41. Cash TF, Thériault J, Annis NM. Body image in an interpersonal context: adult attachment, fear of intimacy and social anxiety. J Soc Clin Psychol. 2004;23:89-103.

42. DeVille DC, Ellmo FI, Horton WA, Erchull MJ. The role of romantic attachment in women's experiences of body surveillance and body shame. Gend Issues. 2015;32:111-20.

43. Pascoal P, Narciso I, Pereira NM. Predictors of body appearance cognitive distraction during sexual activity in men and women. J Sex Med. 2012;9:2849-60.

44. Sanchez DT, Kiefer AK. Body concerns in and out of the bedroom: implications for sexual pleasure and problems. Arch Sex Behav. 2007:36:808-20.

45. Ramseyer Winter V, Teti M, Landor AM, Morris K. "On a journey to appreciate what my body does for me": qualitative results from a positive body image pilot intervention study. Soc Work Public Health. 2019;34:637-45.

46. Ramseyer Winter V, Landor AM, Teti M, Morris K, Schliep EM, PevehousePfeiffer $\mathrm{D}$, et al. Is body appreciation a mechanism of depression and anxiety? An investigation of the 3-Dimensional Body Appreciation Mapping (3D-BAM) intervention. Ment Health Prev. 2019;14:200158.

47. Alleva JM, Martijn C, Van Breukelen GJP, Jansen A, Karos K. Expand your horizon: a programme that improves body image and reduces selfobjectification by training women to focus on body functionality. Body Image. 2015;15:81-9.

48. Johnson S. An emotionally focused approach to sex therapy. In: Peterson ZD, editor. The Wiley handbook of sex therapy. West Sussex: Wiley; 2017. p. 250-65.

49. Basson R. Are healthy parental attachments and resilience to societal objectification basic to women's sexual health? Arch Sex Behav 2019:48:1683-7.

50. Cohen J. Statistical power analysis for the behavioral sciences. 2nd ed. New York: Lawrence Erlbaum Associates Inc; 1988.

51. McCabe MP, Sharlip ID, Lewis R, Atalla E, Balon R, Fisher AD, et al. Risk factors for sexual dysfunction among women and men: a consensus statement from the fourth International Consultation on Sexual Medicine 2015. J Sex Med. 2016;13:153-67.

52. Meston CM, Bradford A. Sexual dysfunctions in women. Annu Rev Clin Psychol. 2007;3:233-56.

53. Sharp G, Tiggemann M, Mattiske J. Predictors of consideration of labiaplasty: an extension of the tripartite influence model of beauty ideals. Psychol Women Q. 2015;39:182-93.

54. Choi BCK, Pak AWP. A catalog of biases in questionnaires. Prev Chronic Dis. 2005;2:Article A13.

55. World Medical Association. World Medical Association Declaration of Helsinki: ethical principles for medical research involving human subjects. JAMA. 2013;310:2191-4

56. American Psychological Association. Ethical principles of psychologists and code of conduct. Am Psychol. 2002;57:1060-73.

\section{Publisher's Note}

Springer Nature remains neutral with regard to jurisdictional claims in published maps and institutional affiliations. 